\title{
FAKTOR-FAKTOR YANG MEMPENGARUHI PARTISIPASI IBU DALAM PENIMBANGAN BALITA DI WILAYAH KERJA PUSKESMAS PARDAMEAN KOTA PEMATANGSIANTAR
}

\author{
AGNES SRY VERA NABABAN ${ }^{1}$, MELVA RINAWATI BUTAR- \\ BUTAR $^{2}$, YULITA ${ }^{3}$, RANI SURAYA 4 \\ 1,2,3,4Prodi S1 Gizi Fakultas Kesehatan Masyarakat, Institut Kesehatan Helvetia, \\ Medan, Indonesia \\ e-mail: verasry89@gmail.com \\ DOI : https://doi.org/10.35451/jkg.v4i1.866
}

\begin{abstract}
One indicator of community participation in the health sector is the coverage of children under five who come and are weighed at the posyandu $(D / S)$. Based on the 2018 Indonesian Health Profile, D/S coverage for toddlers in Indonesia is $67.48 \%$. Some of the factors causing the lack of maternal visits to the posyandu were the mothers' lack of knowledge, the distance to the Posyandu, the role of cadres and family support. Of this study was to determine the factors that influence the participation of mothers in weighing children under five in the working area of Pardamean Health Center, Pematangsiantar. This research method is an analytic study with cross-sectional design with 108 respondents by purposive sampling. The subject is the mother of the toddler who meets the inclusion and exclusion criteria. Primary data were collected in the Pardamean Puskesmas area on $12^{\text {th }}-10^{\text {th }}$. Based on the statistical test of 108 mothers of children under five, there were still 41 mothers who did not participate in weighing children under five by $38 \%$. The results of the chi square analysis show that the relationship between maternal knowledge and maternal participation in weighing children under five is obtained by the $p$ value $=0.000$ ( $p$ <.05), the relationship between Posyandu distance and maternal participation in weighing children under five is obtained by the $p$ value $=0.002$ $(p<0.05)$, the correlation between the role of cadres and the participation of mothers in weighing children under five, is obtained by the $p$ value $=0.000$ ( $p$ <0.05), the relationship between family support and the participation of mothers in weighing children under five is obtained by the $p$ value $=0.017$ ( $p$
\end{abstract}


$<0.05)$. That there is a relationship between maternal knowledge, Posyandu distance, the role of cadres and family support in weighing toddlers in the working area of Pardamean Health Center, Pematangsiantar.

\section{Keywords: Mother's Knowledge, Posyandu Distance, Role of Cadres, Family Support, Mother's Participation.}

\section{PENDAHULUAN}

Status gizi Bayi Dibawah Lima Tahun (balita) berpengaruh sangat besar dalam mewujudkan sumber daya manusia yang berkualitas di masa yang akan datang. Status gizi balita merupakan hal penting yang harus diketahui oleh setiap orang tua. Perlunya perhatian lebih terhadap tumbuh kembang anak di usia balita didasarkan fakta bahwa kurang gizi pada masa emas ini bersifat irreversible (tidak dapat pulih), sedangkan kekurangan gizi dapat mempengaruhi perkembangan otak anak (Marimbi, 2010).

Menurut Riskesdas 2018, prevalensi gizi kurang pada balita di Indonesia yakni $17,7 \%$ terdiri dari gizi buruk 3,9\% dan gizi kurang 13,8\%. Yang berarti terjadi penurunan agak lambat jika dibandingkan tahun 2013 $(19,6 \%)$, tahun $2010(17,9 \%)$ dan tahun 2007 (18,4\%)(Kemenkes, 2018). Untuk provinsi Sumatera Utara, prevalensi gizi kurang pada balita sebesar $18,2 \%$ terdiri dari gizi buruk $5,2 \%$ dan gizi kurang 13\%. Hal ini menunjukkan bahwa prevalensi gizi kurang masih belum mencapai target
RPJMN yakni 15\%. Untuk kota Pematang Siantar, prevalensi gizi kurang pada balita sebesar 14,8\% terdiri dari gizi buruk 2,3\% dan gizi kurang 12,5\% (Kemenkes, 2018).

Salah satu bentuk peran serta masyarakat dalam bidang kesehatan bagi balita adalah Pos Pelayanan Terpadu (Posyandu) yang dibentuk oleh dan untuk masyarakat itu sendiri (Giovani, 2013). Kegiatan pelayanan posyandu balita diantaranya adanya pemantauan tumbuh kembang balita dengan cara melakukan pengukuran berat badan sebagai cara terbaik untuk menilai status gizi balita tiap bulannya, sehingga tumbuh kembang anak akan terpantau (Manadin, 2014). Penimbangan merupakan salah satu kegiatan utama program perbaikan gizi yang menitikberatkan pada pencegahan dan peningkatan keadaan gizi anak. Penimbangan terhadap bayi dan balita yang merupakan upaya masyarakat memantau pertumbuhan dan perkembangannya. Partisipasi masyarakat dalam penimbangan tersebut digambarkan dalam perbandingan jumlah balita yang ditimbang (D) dengan jumlah balita 
seluruhnya (S). Semakin tinggi partisipasi masyarakat dalam penimbangan, maka semakin banyak pula data yang dapat menggambarkan status gizi balita (Dinas Kesehatan Kabupaten Lampung Timur, 2018).

Salah satu indikator partisipasi serta masyarakat di bidang kesehatan adalah cakupan balita yang datang dan ditimbang di posyandu (D/S). Berdasarkan Profil Kesehatan Indonesia 2018, cakupan D/S untuk balita di Indonesia sebesar $67,48 \%$, cakupan D/S untuk balita di provinsi Sumatera Utara sebesar 79,11\%, cakupan D/S untuk balita di kota Pematang Siantar sebesar $64,3 \%$ ternyata lebih rendah dibandingkan target nasional untuk cakupan D/S sebesar 70\%. Berdasarkan data Pelayanan Upaya Gizi di Puskesmas Pardamean kota Pematang Siantar Tahun 2018, cakupan D/S untuk balita sebelumnya sebesar $88,1 \%$ namun pada bulan Mei hanya $47 \%$, bulan Juni mengalami kenaikan menjadi $88 \%$, kemudian mengalami penurunan lagi menjadi 42,5\% pada bulan Juli 2020 .

Faktor yang mendorong ibu berkunjung ke posyandu untuk menimbang anaknya adalah pemantauan pertumbuhan anak karena pemantauan pertumbuhan anak sangat penting dilakukan untuk mengetahui adanya gangguan pertumbuhan secara dini. Untuk mengetahui pertumbuhan tersebut, penimbangan balita setiap bulan sangat diperlukan. Salah satu faktor penyebab kurangnya kunjungan ibu ke posyandu adalah kurangnya pengetahuan ibu, jarak Posyandu, peran kader serta dukungan keluarga (Cahyaningrum, 2019).

Berdasarkan hasil penelitian di Posyandu Kelurahan Tambak harjo Kecamatan Semarang Barat menyimpulkan bahwa ada hubungan antara peran kader dengan keaktifan ibu menimbangkan balita di posyandu $\mathrm{p}=$ $0,000 \quad(p<0,05)$. Peran kader yang memiliki kinerja yang baik dapat memberikan motivasi yang baik kepada Ibu balita agar berkunjung ke Posyandu (Widyaningsih, 2020).

Dukungan keluarga ini sangat berpengaruh dalam suatu tindakan yang akan dilakukan oleh anggota keluarganya, dalam hal ini berpengaruh dalam tingkat partisipasi mengikuti kegiatan cek kesehatan di Posyandu. Dukungan keluarga ini menjadi pondasi dasar untuk menjadi dorongan yang akan dilakukan oleh anggota keluarga dalam memperhatikan kondisi kesehatannya baik yang masih usia produktif hingga yang berusia lansia (Hernilawati, 2013).

Berdasarkan penelitian yang dilakukan di Posyandu Tersanjung di Desa Lueng Keubeu Jagat Kecamatan Tripa Makmur Kabupaten Nagan Raya menunjukan bahwa responden yang mengaku jarak tempuh ke tempat pelaksanaan posyandu dekat, akan lebih banyak memanfaatkan posyandu 
dibandingkan dengan responden yang jarak tempuhnya jauh (Utami, 2016).

Tujuan dari penelitian ini adalah untuk mengetahui faktor-faktor yang mempengaruhi partisipasi ibu dalam penimbangan balita di Wilayah kerja Puskesmas Pardamean Kota Pematangsiantar.

\section{METODE PENELITIAN}

Jenis penelitian ini merupakan penelitian analitik dengan desain crosssectional. Penelitian ini dilakukan di di Wilayah kerja Puskesmas Pardamean Kota Pematangsiantar. Waktu penelitian dilaksanakan mulai dari bulan September sampai Oktober. Populasi dalam penelitian ini adalah semua ibu balita berjumlah 149 yang terdaftar di Wilayah kerja Puskesmas Pardamean Kota Pematangsiantar. Teknik pengambilan sampel dalam penelitian ini menggunakan teknik purposive sampling, dan untuk memenuhi kriteria sampel yaitu sampel dipilih berdasarkan kriteria yang ditetapkan oleh peneliti. Uji statistik yang digunakan yaitu uji chisquare.

\section{HASIL}

\section{Analisis Univariat}

Analisa Univariat dilakukan untuk melihat distribusi frekuensi yang meliputi umur, pendidikan, pekerjaan, partisipasi ibu, pengeahuan ibu, jarak posyandu, peran kader,

Dukungan keluarga.

\section{Distribusi Frekuensi Responden}

Berdasarkan Umur, Jenis Kelamin, dan pendidikan Terakhir Responden

Berdasarkan kelas inteval diperoleh distribusi berdasarkan umur, pendidikan, pekerjaan responden dilihat pada tabel 1 berikut ini.

Tabel 1. Distribusi Frekuensi Karakteristik Responden

\begin{tabular}{|c|c|c|}
\hline Variabel & $f$ & $\%$ \\
\hline \multicolumn{3}{|l|}{ Umur } \\
\hline 17-25 tahun & 33 & 30,6 \\
\hline 26-35 tahun & 62 & 57,4 \\
\hline 36-45 tahun & 13 & 12,0 \\
\hline \multicolumn{3}{|l|}{ Pendidikan } \\
\hline $\begin{array}{l}\text { Dasar } \\
\text { (SD/SMP) }\end{array}$ & 29 & 26,9 \\
\hline $\begin{array}{l}\text { Menengah } \\
(\mathrm{SMA} / \mathrm{SMK})\end{array}$ & 70 & 64,8 \\
\hline $\begin{array}{l}\text { Perguruan } \\
\text { Tinggi }\end{array}$ & 9 & 8,3 \\
\hline \multicolumn{3}{|l|}{ Pekerjaan } \\
\hline Ibu Rumah & 59 & 54,6 \\
\hline \multicolumn{3}{|l|}{ Tangga } \\
\hline Buruh & 11 & 10,2 \\
\hline Petani & 3 & 2,8 \\
\hline PNS & 26 & 24,1 \\
\hline Wiraswasta & 9 & 8,3 \\
\hline
\end{tabular}

Berdasarkan tabel 1.
menunjukkan bahwa dari 108 Ibu di wilayah kerja Puskesmas Pardamean, kelompok umur tertinggi pada masa dewasa awal (26-35 tahun) sebesar $57,4 \%$ dan terendah kelompok umur masa dewasa akhir (36-45 tahun) 
sebesar 12\%. Menunjukkan bahwa tingkat Pendidikan Ibu sebagian besar $(64,8 \%)$ berada dalam kategori menengah yaitu sebanyak 70 orang. Menunjukkan bahwa sebagian besar Pekerjaan Ibu sebagai Ibu rumah tangga yakni sebesar $54,6 \%$.

\section{Distribusi Frekuensi Variabel} Penelitian Karakteristik Responden Pendidikan,Pekerjaan, Partisipasi Ibu, dan Pengetahuan Ibu Balitadi Wilayah Kerja Puskesmas Pardamean

Berdasarkan kelas inteval diperoleh distribusi partisipasi ibu, pengetahuan, jarak posyandu, peran kader, dukungan keluarga responden dilihat pada tabel 2 dibawah ini.

Tabel 2. Distribusi Frekuensi Variabel Penelitian

\begin{tabular}{lcc}
\hline Variabel & $\mathrm{f}$ & $\%$ \\
\hline Partisipasi Ibu & & \\
\hline Berkunjung & 67 & 62 \\
Tidak & 41 & 38 \\
Berkunjung & & \\
\hline Pengetahuan & & \\
\hline Kurang & 48 & 44,4 \\
Baik & 60 & 55,6 \\
\hline Jarak Posyandu & & \\
\hline Dekat & 74 & 68,5 \\
Jauh & 34 & 31,5 \\
\hline Peran Kader & & \\
\hline Kurang & 46 & 42,6 \\
Berperan & & \\
Berperan & 62 & 57,4 \\
\hline
\end{tabular}

\begin{tabular}{lcc}
\hline $\begin{array}{l}\text { Dukungan } \\
\text { Keluarga }\end{array}$ & & \\
\hline $\begin{array}{l}\text { Kurang } \\
\text { Mendukung } \\
\text { Mendukung }\end{array}$ & 40 & 37 \\
\hline Total & 68 & 63 \\
\hline
\end{tabular}

\section{Berdasarkan}

tabel 2. Menunjukkan bahwa dari 108 Ibu yang Berpartisipasi dalam penimbangan balita sebanyak 41 orang yang tidak berkunjung yakni sebesar 38\% dan 67 orang yang berkunjung yakni sebesar $62 \%$.Menunjukkan bahwa ibu balita memiliki Pengetahuan yang baik sebesar $55,6 \%$ dan pengetahuan kurang sebesar 44,4\%. Menunjukkan bahwa ibu balita memiliki Jarak Rumah yang dekat dengan Posyandu yakni sebesar 68,5\% dan yang jauh sebesar $31,5 \%$.Menunjukkan bahwa Kader yang sudah cukup berperan sebesar $57,4 \%$ dan yang kurang berperan sebesar 42,6\%.Menunjukkan bahwa sebanyak 68 Ibu memiliki Dukungan dari Keluarga untuk ke Posyandu yakni sebesar 63\%.

Analisis Bivariat dilakukan untuk mengetahui faktor-faktor yang mempengaruhi partisipasi ibu dalam penimbangan balita di Wilayah kerja Puskesmas Pardamean Kota Pematangsiantar.

$$
\begin{aligned}
& \text { Hubungan Pengetahuan Ibu, Jarak } \\
& \text { Posyandu, Peran Kader, Dukungan } \\
& \text { Keluarga Terhadap Partisipasi Ibu }
\end{aligned}
$$




\section{dalam Penimbangan Balita di \\ Wilayah Kerja Puskesmas \\ Pardamean}

Tabel 3. Hubungan Pengetahuan Ibu dengan Partisipasi Ibu dalam Penimbangan Balita di Wilayah Kerja Puskemas Pardamean Tahun 2020

\begin{tabular}{|c|c|c|c|c|c|c|}
\hline \multirow{3}{*}{ Variabel } & \multicolumn{4}{|c|}{ Partisipasi Ibu } & \multirow{3}{*}{ Total } & \multirow{3}{*}{$p$-value } \\
\hline & \multicolumn{2}{|c|}{ Berkunjung } & \multicolumn{2}{|c|}{ Tidak Berkunjung } & & \\
\hline & $f$ & $\%$ & $f$ & $\%$ & & \\
\hline \multicolumn{7}{|c|}{ Pengetahuan Ibu } \\
\hline Kurang & 8 & 11,9 & 40 & 97,6 & 48 & \multirow{2}{*}{0,000} \\
\hline Baik & 59 & 88,1 & 1 & 2,4 & 60 & \\
\hline \multicolumn{7}{|c|}{ Jarak Posyandu } \\
\hline Dekat & 53 & 79,1 & 21 & 51,2 & 74 & \multirow{2}{*}{0,002} \\
\hline Jauh & 14 & 20,9 & 20 & 48,8 & 34 & \\
\hline \multicolumn{7}{|l|}{ Peran Kader } \\
\hline Kurang & 9 & 13,4 & 37 & 90,2 & 46 & \multirow{3}{*}{0,000} \\
\hline Berperan & & & & & & \\
\hline Berperan & 58 & 86,6 & 4 & 9,8 & 62 & \\
\hline \multicolumn{7}{|c|}{ Dukungan Keluarga } \\
\hline Kurang & 19 & 28,4 & 21 & 51,2 & 40 & \multirow{3}{*}{0,017} \\
\hline Mendukung & & & & & & \\
\hline Mendukung & 48 & 71,6 & 20 & 48,8 & 68 & \\
\hline
\end{tabular}

\section{Berdasarkan tabel 3. \\ menunjukkan bahwa Ibu dengan \\ pengetahuan yang kurang ikut}

berpartisipasi dalam penimbangan balita ke Posyandu hanyasebesar $11,9 \%$ dan yang tidak ikut berpartisipasi sebesar $97,6 \%$ sedangkan ibu dengan pengetahuan yang baik ikut berpartisipasi dalam penimbangan balita ke Posyandu sebesar $88,1 \%$ dan yang tidak ikut berpartisipasi sebesar 2,4\%.

Hasil analisis statistik diperoleh nilai $p$-value $0,000 \quad(p<0,05)$ yang bermakna ada hubungan pengetahuan ibu dengan partisipasi ibu dalam penimbangan balita di wilayah kerja Puskesmas Pardamea. 
Berdasarkan tabel 3. menunjukkan bahwa Ibu dengan jarak posyandu yang dekat dari rumah ikut berpartisipasi dalam penimbangan balita ke Posyandu sebesar $79,1 \%$ dan yang tidak ikut berpartisipasi sebesar $51,2 \%$ sedangkan ibu dengan jarak posyandu yang jauh ikut berpartisipasi dalam penimbangan balita ke Posyandu hanyasebesar 20,9\% dan yang tidak ikut berpartisipasi sebesar 48,8\%.

Hasil analisis statistik diperoleh nilai $p$-value0,002 $(p<0,05)$ yang bermakna ada hubungan jarak posyandu dengan partisipasi ibu dalam penimbangan balita di wilayah kerja Puskesmas Pardamean tahun 2020

$$
\text { Berdasarkan tabel } 3 .
$$
menunjukkan bahwa kader yang kurang berperanmemiliki ibu balita yang berpartisipasi dalam penimbangan balita ke Posyandu hanya sebesar $13,4 \%$ dan yang tidak ikut berpartisipasi sebesar $90,2 \%$ sedangkan kader yang cukup berperan memiliki ibu yang ikut berpartisipasi dalam penimbangan balita ke Posyandu sebesar $86,6 \%$ dan yang tidak ikut berpartisipasi sebesar $9,8 \%$.

Hasil analisis statistik diperoleh

nilai $p$-value $0,000 \quad(p<0,05)$ yang bermakna ada hubungan peran kader dengan partisipasi ibu dalam penimbangan balita di wilayah kerja Puskesmas Pardamean.

$$
\text { Berdasarkan tabel } 3 .
$$
menunjukkan bahwa keluarga yang kurang mendukung memiliki ibu balita yang berpartisipasi dalam penimbangan balita ke Posyandu hanya sebesar $28,4 \%$ dan yang tidak ikut berpartisipasi sebesar $51,2 \%$ sedangkan keluarga yang mendukung memiliki ibu yang ikut berpartisipasi dalam penimbangan balita ke Posyandu sebesar $71,6 \%$ dan yang tidak ikut berpartisipasi sebesar 48,8\%. Hasil analisis statistik diperoleh nilai $p$-value $0,017 \quad(p<0,05) \quad$ yang bermakna ada hubungan dukungan keluarga dengan partisipasi ibu dalam penimbangan balita di wilayah kerja Puskesmas Pardamean.

\section{PEMBAHASAN}

\section{Pengetahuan Ibu}

Pengetahuan adalah hasil dari tahu, dan terjadi setelah orang melakukan penginderaan (penglihatan, pendengaran, penciuman, rasa, dan raba) terhadap suatu objek tertentu. Sebagian besar pengetahuan manusia diperoleh melalui mata dan telinga. Pengetahuan merupakan domain yang sangat penting dalam membentuk tindakan seseorang, jadi pengetahuan yang baik akan membuat ibu-ibu balita lebih aktif lagi ke posyandu karena dari banyaknya informasi yang telah diperolehnya. Salah satu faktor yang mempengaruhi perilaku seseorang adalah pengetahuan, karena dengan pengetahuan maka akan menghasilkan perubahan atau peningkatan pengetahuan. Perilaku yang dilakukan dengan berdasarkan pada pengetahuan akan bertahan lebih lama dan 
kemungkinan menjadi perilaku yang melekat pada seseorang dibandingkan jika tidak berdasarkan pengetahuan ibu balita yang memiliki pengetahuan yang kurang akan cenderung mengabaikan kesehatan dan pada akhirnya akan memiliki tindakan yang akan membahayakan bagi dirinya sendiri dan balitanya. Ibu balita yang memiliki pengetahuan kurang tentang posyandu akan memilih perilaku yang kurang tepat untuk tidak melakukan kunjungan ke posyandu.

Berdasarkan hasil penelitian ini, ibu dengan pengetahuan yang baik ikut berpartisipasi dalam penimbangan balita ke Posyandu sebesar $88,1 \%$ sedangkan ibu dengan pengetahuan yang kurang ikut berpartisipasi dalam penimbangan balita ke Posyandu hanya sebesar $11,9 \%$. Hasil analisis statistik diperoleh nilai $p$-value $0,000 \quad(p<0,05) \quad$ yang bermakna ada hubungan pengetahuan ibu dengan partisipasi ibu dalam penimbangan balita di wilayah kerja Puskesmas Pardamean.

Berdasarkan fakta yang telah ditemukan dalam penelitian yang dilakukan di wilayah kerja Puskesmas Pardamean, maka sebaiknya ibu membawa balitanya untuk ditimbang agar mengetahui kondisi pertumbuhan balita. Permenkes RI tahun 2014 menyatakan bahwa anak balita adalah anak umur 0-59 bulan wajib dibawa keposyandu, perlu diketahui pertumbuhan dan perkembangan mengalami peningkatan yang pesat pada usia dini yaitu pada umur 0-59 bulan, dimana pada rentang umur ini perkembangan anak mencapai 50\% dari seluruh perkembangannya yang akan mencapai $100 \%$ pada umur 18 tahun.

Berdasarkan asumsi peneliti di dapatkan bahwa dengan pengetahuan yang baik yang dimiliki ibu balita mengenai posyandu, maka ada kecenderungan berpengaruh terhadap terbentuknya perilaku yaitu ibu balita dapat berpartisipasi aktif ke Posyandu. Ibu balita dengan pengetahuan tinggi pada umumnya memiliki cakupan penimbangan yang baik untuk pemantauan tumbuh kembang balitanya, hal ini disebabkan karena ibu balita mengerti tentang manfaat dari kegiatan Posyandu. Sedangkan ibu balita yang memiliki pengetahuan rendah tidak memiliki cakupan penimbangan balita yang baik, hal ini disebabkan adanya asumsi bahwa kegiatan Posyandu hanya untuk mendapatkan imunisasi sehingga ketika balitanya sudah mendapatkan imunisasi lengkap tidak perlu lagi berkunjung ke Posyandu untuk menimbang balitanya.

\section{Jarak Posyandu}

Jarak adalah ruang sela (panjang atau jauh) antara dua benda atau tempat yaitu jarak antara rumah dengan posyandu. Jangkauan pelayanan posyandu dapat ditingkatkan dengan bantuan pendekatan maupun 
pemantauan melalui kegiatan posyandu sebaiknya berada pada tempat yang mudah dijangkau oleh masyarakat.

Jarak rumah dekat dengan partisipasi aktif menimbang balitanya ke Posyandu $68,5 \%$ sedikit lebih tinggi dibanding dengan responden yang jarak rumahnya jauh dan aktif menimbang balitanya ke Posyandu yaitu 31,5\%. Hasil analisis bivariat menunjukan bahwa tidak ada hubungan yang signifikan antara jarak rumah yang dekat Posyandu dan jarak yang jauh dari Posyandu dengan partisipasi ibu dalam menimbang balita ke Posyandu. Hasil analisis statistik diperoleh nilai p-value $0,002 \quad(p<0,05)$ yang bermakna ada hubungan jarak posyandu dengan partisipasi ibu dalam penimbangan balita di wilayah kerja Puskesmas Pardamean.

Hal tersebut sesuai dengan yang dinyatakan oleh Sulistyorini (2010) bahwa salah satu kendala pelaksanaan posyandu adalah tempat pelaksanaan posyandu yang kurang representatif. Jarak dalam penelitian ini adalah ukuran jauh dekatnya rumah sampai ke posyandu. Posyandu sebaiknya berada pada tempat yang mudah dijangkau oleh masyarakat dan ditentukan oleh masyarakat sendiri agar masyarakat mudah menjangkaunya.

Hasil penelitian ini menunjukkan bahwa jarak rumah memiliki hubungan dengan partisipasi kunjungan balita ke posyandu. Penelitian ini sejalan dengan penelitian yang dilakukan Nurena (2012) bahwa ada hubungan yang signifikan antara jarak rumah dengan pemanfaatan posyandu di Suku Bajo Desa Mola Selatan Kabupaten Wakatobi. Penelitian lain yang sesuai yaitu yang dilakukan oleh Kurnia (2011) bahwa ada hubungan antara jarak tempuh dari rumah ke posyandu dengan partisipasi ibu balita dalam pemanfaatan pelayanan gizi di posyandu.

\section{Peran Kader}

Kader merupakan fasilitator tenaga kesehatan yang berada di tengah masyarakat untuk mengorganisir terlaksananya program posyandu serta berperan aktif memberikan motivasi kepada ibu balita dan ibu yang memiliki balita di komunitas setempat. Karena bersifat sukarela, maka tidak ada jaminan kader tetap melaksanakan tugasdan perannya dengan baik dalam pelaksanaan program posyandu, seperti kader yang lebih mengutamakan keluarganya sendiri dibandingkan dengan jadwal penimbangan posyandu secara rutin tiap bulannya.

Keberadaan kader sangat dibutuhkan sebagai salah satu sistem penyelenggarakan pelayanan di posyandu. Mereka adalah titik awal pelayanan kesehatan di komunitas dan merupakan fasilitator bagi warga yang mengalami sakit sebelum dirujuk ke Puskesmas. Keberadaan posyandu dengan pelaksanaan program Deteksi 
Dini Tumbuh Kembang (DDTK) merupakan kunci dan motivator bagi para ibu balita untuk mau belajar mendeteksi dini tumbuh kembang buah hati mereka. Di harapkan kader mampu memberikan peran yang lebih kepada masyarakat sebagai bentuk pengabdian, kemampuan kader sebagai rujukan masyarakat dalam menyampaikan masalah pada tumbuh kembang balita akan sangat membantu tenaga kesehatan dalam pengambilan keputusan terhadap kasus yang ada dimasyarakat.

Hasil dari penelitian ini yakni kader yang kurang berperan memiliki ibu balita yang berpartisipasi dalam penimbangan balita ke Posyandu hanya sebesar $13,4 \%$ sedangkan kader yang berperan baik memiliki ibu yang ikut berpartisipasi dalam penimbangan balita ke Posyandu yakni sebesar $86,6 \%$. Hasil analisis statistik diperoleh nilai $\mathrm{p}$-value $0,002(p<0,05)$ yang bermakna ada hubungan jarak posyandu dengan partisipasi ibu dalam penimbangan balita di wilayah kerja Puskesmas Pardamean.

$$
\text { Menurut asumsi peneliti }
$$
hubungan antara peran kader dengan partisipasi ibu dalam penimbangan balita cukup signifikan dikarenakan hasil pengolahan data menunjukkan sebagian besar peran kader sudah baik sehingga tingkat partisipasi balita ke posyandu juga baik, beda halnya dengan peran kader yang buruk maka akan membuat balita ke posyandu jadi enggan untuk ikut berpartisipasi ke posyandu.

\section{Dukungan Keluarga}

Dukungan keluarga ini sangat berpengaruh dalam suatu tindakan yang akan dilakukan oleh anggota keluarganya, dalam hal ini berpengaruh dalam tingkat partisipasi mengikuti kegiatan cek kesehatan di Polindes. Dukungan keluarga ini menjadi pondasi dasar untuk menjadi dorongan yang akan dilakukan oleh anggota keluarga dalam memperhatikan kondisi kesehatannya baik yang masih usia produktif hingga yang berusia lansia.

Sumber dukungan keluarga adalah sumber dukungan yang berupa dukungan secara internal seperti dukungan dari suami/istri, dukungan dari orangtua, dukungan dari saudara kandung atau dukungan sosial keluarga secara eksternal seperti paman dan bibi. Perilaku kesehatan seseorang ditentukan oleh ada tidaknya dukungan sosial dari masyarakat sekitarnya. Apabila dikaitkan dengan teori tersebut, maka dukungan keluarga sebagai salah satu bentuk dukungan sosial yang merupakan faktor yang mempengaruhi perilaku ibu balita dalam penimbangan balita ke Posyandu.

Hasil penelitian ini menunjukkan bahwa keluarga yang kurang mendukung memiliki ibu balita yang berpartisipasi dalam penimbangan balita ke Posyandu hanya sebesar $28,4 \%$ dan 
yang tidak ikut berpartisipasi sebesar $51,2 \%$ sedangkan keluarga yang mendukung memiliki ibu yang ikut berpartisipasi dalam penimbangan balita ke Posyandu sebesar $71,6 \%$ dan yang tidak ikut berpartisipasi sebesar $48,8 \%$. Hasil analisis statistik diperoleh nilai $p$ value $0,017(p<0,05)$ yang bermakna ada hubungan dukungan keluarga dengan partisipasi ibu dalam penimbangan balita di wilayah kerja Puskesmas Pardamean.

Penelitian ini sejalan dengan penelitian yang dilakukan Helna (2012) tentang hubungan dukungan keluarga dengan perilaku ibu membawa balita ke posyandu di Kabupaten Pesawara dimana nilai $p$ value $=0,004$ yang lebih kecil dari $\alpha(0,05)$ sehingga dapat disimpulkan bahwa Ho ditolak dan $\mathrm{Ha}$ diterima, sedangkan nilai $\mathrm{OR}=6,469$ yang berarti ibu dengan dukungan keluarga memiliki peluang membawa balita keposyandu 6,469 lebih besar dari yang tidak ada dukungan keluarga. Menurut asumsi peneliti, ibu balita yang mendapat dukungan dari keluarganya cenderung lebih aktif dalam melakukan penimbangan balita ke Posyandu.

Menurut asumsi peneliti bahwa masih rendahnya cakupan penimbangan balita ke Posyandu dikarenakan oleh faktor dukungan keluarga. Oleh karena itu ada hubungan dukungan keluarga dengan partisipasi ibu dalam penimbangan balita ke Posyandu. Ibu balita yang mendapatkan dukungan yang baik dari keluarga pada umumnya masih memiliki partisipasi penimbangan balita yang tinggi, hal ini kemungkinan disebabkan karena dukungan keluarga selalu mengingatkan jadwal Posyandu dan memberikan dorongan untuk membawa balitanya ke Posyandu. Sedangkan ibu balita yang memiliki dukungan keluarga yang kurang baik, tidak memiliki partisipasi penimbangan balita yang tinggi, kemungkinan disebabkan karena tidak adanya anggota keluarga yang menggantikan ibu untuk membawa balitanya ke Posyandu ketika ibu bekerja.

\section{KESIMPULAN}

Ada hubungan pengetahuan ibu, jarak Posyandu, peran kader serta dukungan keluarga dalam penimbangan balita di wilayah kerja Puskesmas Pardamean kota Pematangsiantar tahun 2020

\section{DAFTAR PUSTAKA}

Cahyaningrum M. (2019). FAKTORFAKTOR YANG BERHUBUNGAN DENGAN KEAKTIFAN IBU BALITA DALAM KEGIATAN POSYANDU DI POSYANDU NUSA INDAH DESA JENAR KECAMATAN JENAR KABUPATEN SRAGEN. JURNAL CHEM INF MODEL. Vol 1:2.

Dinas Kesehatan Kabupaten Lampung Timur. (2018). Evaluasi Tahunan Program Gizi Tahun 2017. Lampung Timur. 
Giovani L. (2013). HUBUNGAN ANTARA KARAKTERISTIK IBU BALITA DENGAN KUNJUNGAN BALITA DALAM KEGIATAN POSYANDU DI KELURAHAN GENUKSARI KECAMATAN GENUK KOTA SEMARANG TAHUN 2013 [SKRIPSI]. SEMARANG: ILMU KEOLAHRAGAAN JURUSAN ILMU KESEHATAN.

Helna, Fatma, Khoidar Amirus, Gunawan Irianto. (2012). HUBUNGAN KEAKTIFAN KADER DAN DUKUNGAN KELUARGA DENGAN PERILAKU IBU MEMBAWA ANAK BALITA KE POSYANDU DI DESA BANDING AGUNG WILAYAH KERJA PUSKESMAS PEDADA KABUPATEN PESAWARAN TAHUN 2012. JURNAL DUNIA KESMAS, Vol (1) No. 2, Halaman: 1-6.

Hernilawati. (2013). HUBUNGAN ANTARA PENGETAHUAN DAPAT MEMPENGARUHI KEPATUHAN IBU MENGGUNAKAN ALAT KONTRASEPSI [SKRIPSI]. Medan: FKM USU.

Kemenkes RI. (2018). Profil Kesehatan Indonesia 2018. Pusat Data Dan Informasi. Jakarta: Departemen Kesehatan RI.

Kemenkes RI. (2018). Hasil Utama Riset Kesehatan Dasar. Pusat Data Dan Informasi. Jakarta: Departemen Kesehatan RI.

Kurnia, N. (2011). FAKTOR-FAKTOR YANG BERHUBUNGAN DENGAN
PARTISIPASI IBU BALITA DALAM PEMANFAATAN PELAYANAN GIZI BALITA DI POSYANDU, KELURAHAN SUKASARI KECAMATAN TANGGERANG TAHUN 2011. SKRIPSI. Program Sarjana Kesehatan Masyarakat UIN.

Manadin. (2014). FAKTOR-FAKTOR YANG BERHUBUNGAN DENGAN KETIDAKHADIRAN BALITA DI POSYANDU DESA TAMBAHARJO KECAMATAN PATI KABUPATEN DATI II PATI [THESIS]. Semarang: IImu Gizi FK UNDIP.

Marimbi H. (2010). Tumbuh Kembang, Status Gizi, Dan Imunisasi Dasar Pada Balita. Yogyakarta: Nuha Medika.

Nurena. (2012). FAKTOR-FAKTOR YANG BERHUBUNGAN DENGAN PEMANFAATAN POSYANDU DI SUKU BAJO DESA MOLA SELATAN KABUPATEN WAKATOBI. MAKASSAR: STIKES NANI HASANUDDIN.

Sulistyorini. (2010). Posyandu dan desa Siaga. Yogyakarta: Nuha Medika.

Utami RB, Damayanti DF. (2016). FAKTOR-FAKTOR YANG BERHUBUNGAN DENGAN PERILAKU IBU DALAM MELAKUKAN KUNJUNGAN KE POSYANDU. JURNAL VOKASI KESEHATAN. Vol. 2(1):41-8.

Widyaningsih TS, Windyastuti W, Tamrin T. (2020). PERAN KADER DALAM MEMOTIVASI IBU BALITA YANG 
Jurnal Kesehatan Masyarakat \& Gizi, e-ISSN: 2655-0849

Vol.4 No.1 Edisi Mei-Oktober 2021

https://ejournal.medistra.ac.id/index.php/JKG

Received: 08 Oktober 2021 :: Accepted: 25 Oktober 2021 :: Published: 31 Oktober 2021

BERKUNJUNG KE POSYANDU.

5(1):1-12.

JURNAL KEPERAWATAN. Vol 